\title{
Estimating the Loss Ratio of Solar Photovoltaic Electricity Generation through Stochastic Analysis
}

\author{
Taehoon Hong ${ }^{1}$, Choongwan $\mathrm{Koo}^{2}$ and Minhyun Lee
}

Accepted February 1, 2013

\begin{abstract}
As climate change and environmental pollution become one of the biggest global issues today, new renewable energy, especially solar photovoltaic (PV) system, is getting great attention as a sustainable energy source. However, initial investment cost of $P V$ system is considerable, and thus, it is crucial to predict electricity generation accurately before installation of the system. This study analyzes the loss ratio of solar photovoltaic electricity generation from the actual PV system monitoring data to predict electricity generation more accurately in advance. This study is carried out with the following five steps: (i) Data collection of actual electricity generation from PV system and the related information; (ii) Calculation of simulation-based electricity generation; (iii) Comparative analysis between actual electricity generation and simulation-based electricity generation based on the seasonality; (iv) Stochastic approach by defining probability distribution of loss ratio between actual electricity generation and simulation-based electricity generation; and (v) Case study by conducting Monte-Carlo Simulation (MCS) based on the probability distribution function of loss ratio. The results of this study could be used (i) to estimate electricity generation from $P V$ system more accurately before installation of the system, (ii) to establish the optimal maintenance strategy for the different application fields and the different season, and (iii) to conduct feasibility study on investment at the level of life cycle.
\end{abstract}

Keywords: Solar photovoltaic system, Loss ratio, Electricity generation, Energy simulation, Stochastic analysis

\section{INTRODUCTION}

As climate change and environmental pollution become global issues, the world has exerted various efforts to save energy and reduce greenhouse gas emissions through international agreements, such as the Kyoto Protocol or the Bali Roadmap. The South Korean government has also set its national carbon emissions reduction target (CERT) at a $30 \%$ reduction of business-as-usual (BAU) carbon emissions by 2020, based on its Low-Carbon and Green Growth Policy [1-2].

As part of such global greenhouse gas emissions reduction to prevent global warming, many countries have started focusing on distributing new renewable energy (NRE) and promoting its industry. By 2009, NRE already supplied $25 \%$ of the world's power generation facilities (1230GW out of a total of $4800 \mathrm{GW}$ ), and $18 \%$ of the total electricity generation. Particularly, the ratio of NRE to the newly built power plants since 2008 in the USA and Europe is higher than the ratio of fossil energy. According to the United Nations Environment Program (UNEP), NRE occupies over $50 \%$ of the new power generation installed in the USA and Europe since 2009. Also, the <World Energy Outlook 2010> of the International Energy Agency (IEA), which was published in November 2010, analyzed that the NRE production ratio would increase by two-fold. That is, NRE power production using photovoltaic, wind energy, and hydroelectricity would increase by $33 \%$ in 2035 , a similar level to the coal power generation ratio. The NRE power production in Scotland, UK, occupies $25 \%$ of the total power production in 2010 [3-4].

To expand NRE distribution, the South Korean government is promoting various systems in public institutions, beginning with the Renewable Energy Dissemination Program. Its NRE distribution policies include the 1 Million Green Homes Program, the Regional Deployment Subsidy Program, the Loans and Tax Incentive Program, the Mandatory NRE Installation Program, and Feed in Tariff (FIT) [5]. The South Korean government estimated that the promotion of such NRE dissemination programs would reduce 12,162 tons of $\mathrm{CO} 2$ yearly, as well as minimize atmospheric pollutants each year, which would result in saving 218 million won yearly and creating a total of 2.189 billion won of economic added value for the next 10 years.

Among the NREs, the photovoltaic system (PV system), in particular, has the highest potential, and is considered a clean and sustainable energy source. Among the NRE

\footnotetext{
${ }^{1}$ Associate Professor, Department of Architectural Engineering, Yonsei University, Seoul, Korea, hong7@yonsei.ac.kr (*Corresponding Author)

2 Department of Architectural Engineering, Yonsei University, Seoul, Korea

${ }^{3}$ Department of Architectural Engineering, Yonsei University, Seoul, Korea
} 
facilities currently installed in public institutions and schools in Seoul, 153 of them are photovoltaic facilities, 106 are solar heat systems, 1 is a wind energy system, 10 are geothermal energy systems, 4 are bio-energy systems, and 3 are fuel cell systems [6].

However, the initial investment cost for a PV system is considerable, and, thus, it is crucial to predict electricity generation accurately before the system is installed. Furthermore, estimating the electricity generation of a PV system through NRE simulation may lead to some uncertainties due to climate factors, pollutants, lack of maintenance, shading, or simulation errors. Therefore, it is necessary to accurately estimate electricity generation by considering loss due to such uncertainties before installing a PV system.

Previous studies have examined various issues related to power loss of a PV system. First, many studies have focused on estimating power loss factors on electricity generation of PV systems. A study estimated the loss factors of a PV system using the sophisticated verification method (SV method) based on the field operation data. The SV method categorizes loss factors in the operation of a PV system into six factors, based on system specification: (i) shading effect; (ii) losses due to incident angle; (iii) load mismatch; (iv) efficiency decrease by temperature; (v) inverter losses; and (vi) other losses. The result of the evaluation on NEDO FT systems determined load mismatch and other losses as major loss factors [7]. Another study aimed to develop a methodology to estimate the uncertainty in PV system yield prediction, and to propose a method to reduce such uncertainty. Through a case study, this study estimated the following kinds of uncertainty: (i) $3.9 \%$ for year-to-year climate variability; (ii) $5 \%$ for long-term average horizontal insolation; (iii) $3 \%$ for estimation of radiation in the plane of the array; (iv) $3 \%$ for power rating of modules; (v) $2 \%$ for losses due to dirt and soiling; (vi) $1.5 \%$ for losses due to snow; and (vii) $5 \%$ for other sources of error. Finally, the following methods were proposed to reduce such uncertainty: i) increase in the reliability in solar radiation estimation; and ii) a survey on power loss due to pollutants (dirt, soil, or snow) that had not been sufficiently documented [8]. Another study developed a model to estimate angular losses due to the incidence angle of solar radiation and surface soil [9]. Still, another study proposed a simple formula to estimate the loss resistances of a PV crystalline silicon module [10].

Second, other studies have analyzed power loss factors in relation to the electricity generation of a PV system. A study has conducted to analyze the reasons for energy loss in the actual operation stage of a PV system, which consequently fails to produce maximum power. A main reason for energy loss in the summer is the inevitability of PV array over-sizing that is required in supplying the load in the winter when solar energy is limited. Other causes for power loss include PV array and battery mismatch, battery, and PV array disconnection [11]. A study has analyzed power loss due to soiling. Once dust accumulates on the PV module surface, the amount of solar radiation that reaches the PV system is reduced, causing power loss. Furthermore, such dust particles change the dependence on the angle of incidence of solar radiation. Therefore, the study quantified radiation losses due to soiling on the PV module surface. The result showed that the mean of the daily solar radiation losses in a year by soling was $4 \%$. If there is no rain for a long time, the daily solar radiation losses would increase by over $20 \%$ [12].

Third, other studies have estimated and assessed the electricity generation of a PV system. A study has developed a calculation method to estimate the energy production of a PV system by using irradiance-domain integrals and the definition of a statistical moment [13]. Another study has conducted a performance and loss analysis of a residential PV system based on the SV method. The result showed that the PV system facing the south had about $22 \%$ more reference yield than others that do not face the south. Also, the performance ratio was different among PV modules by different manufacturers by over $10 \%$, whereas the difference in the module arrangement had little effect on performance. Key loss factors that determine the performance ratio of each system performance were Power Conditioning System (PCS), module temperature, reflection, and system peak power loss [14].

As such, various studies have been conducted on the power loss of a PV system. These previous studies have focused on specific power loss factors or the estimation of electricity generation of a PV system. However, there are only few studies that estimate the electricity generation of a PV system by considering all power loss factors. Also, each power loss factor was considered separately, which resulted in complicated methodologies and problems in application.

Therefore, this study aimed to produce a loss ratio of the monthly electricity generation by analyzing the difference in actual electricity generation and simulation-based electricity generation. The application of the proposed loss ratio to the estimation of electricity generation of a $\mathrm{PV}$ system would allow us to estimate electricity generation more accurately and easily. Toward this end, the study used the actual electricity generation data of the PV system installed in public facilities and schools in Seoul between 2008 and 2011.

This study is carried out with the following five steps: (i) Data collection of actual electricity generation from PV system and the related information; (ii) Calculation of simulation-based electricity generation; (iii) Comparative analysis between actual electricity generation and simulation-based electricity generation based on the seasonality; (iv) Stochastic approach by defining probability distribution of loss ratio between actual electricity generation and simulation-based electricity generation; and (v) Case study by conducting Monte-Carlo Simulation (MCS) based on the probability distribution function of loss ratio. 


\section{ESTABLISHMENT OF DATABASE}

\section{A. Data Collection}

Seoul is continuously promoting NRE system in public organizations through the NRE distribution program. As of 2011, 153 organizations out of all the public facilities and schools in Seoul have a PV system, and out of the PV systems that were installed as part of the government subsidy (1 Million Green Homes Program, Regional Deployment Subsidy Program, Loans and Tax Incentive Program, Mandatory Renewable Energy Installation Program, and Feed in Tariff (FIT)), the data on the current production condition of the facilities, in which a monitoring system is built, are collected and maintained by the New Renewable Energy Center of the Korea Energy Management Corporation (KEMCO). The target facilities are those whose generation capacity per system is over $10 \mathrm{~kW}$ for projects done before January 14,2010 , or $50 \mathrm{~kW}$ after January 15, 2010 [5-6,15].

Through interviews with experts, including the staff at KEMCO, the study collected the monthly electricity generation data, as well as the capacity of PV systems installed in about 70 facilities. The collected data correspond to the electricity generation data between 2008 and 2011, and if the year of the installation is after 2008, they correspond to the electricity generation data from the year of the installation to 2011 .

\section{B. Calculation of simulation-based electricity generation}

To compare the actual electricity generation and the simulation-based electricity generation of PV systems installed in public facilities in Seoul, the study calculated the simulation-based electricity generation annually (2008 to 2011) by using NRE simulation program called 'RETScreen'. Having been co-developed by experts from the Department of National Resources in Canada and the United Nations Environment Programme, it is believed that 'RETScreen' provides public confidence. Accordingly, the study assumed that the electricity generation from 'RETScreen' is the theoretical or ideal electricity generation. To calculate the simulation-based electricity generation using 'RETScreen', the PV panel and inverter information, as well as the installation angle of the solar panel, should be first determined. The solar cell, as a component of a PV panel, can be divided into crystalline silicon solar cells and amorphous silicon cells based on the material. In the PV system market in South Korea, the mono-crystalline solar module and the multi-crystalline module among crystalline silicon solar cell types are most widely used [16]. Through market research, the study selected and applied the PV panel and inverter that is most widely commercialized when processing the simulation (refer to Table I) [17]. Also, the study set $30^{\circ}$, the recommended installation angle of a solar panel by Seoul City, as the installation angle of the solar panel [18]. Weather data are also required in calculating the simulation-based electricity generation by using 'RETScreen', and among them, daily solar radiation (DSR) is a climate factor that greatly affects electricity generation. Therefore, to calculate the simulation-based electricity generation more accurately, the study used the actual daily solar radiation in the simulation. The measured daily solar radiation was collected by the Korea Meteorological Administration (KMA) [19].

TABLE I

PROFILE OF THE PV SYSTEM

\begin{tabular}{ccc}
\hline Classification & PV panel & PV inverter \\
\hline Model name & SM-200PD0 & PV-C350S/H \\
Power capacity (w) & 200 & 50,000 \\
Model & 14 & 92 \\
$\begin{array}{c}\text { efficiency (\%) } \\
\text { Miscellaneous } \\
\text { losses (\%) }\end{array}$ & 3 & 3 \\
\hline
\end{tabular}

\section{DRAWING LOSS RATIO THROUGH THE COMPARISON OF ACTUAL ELECTRICITY GENERATION AND SIMULATION- BASED ELECTRICITY GENERATION}

\section{A. Removal of outliers using boxplot}

To conduct a statistical comparison between the actual and simulation-based electricity generation of PV systems installed in public facilities in Seoul, the study categorized corresponding data by month (from January to December), and calculated the error rate (ER) and the mean absolute percentage error (MAPE) of each type of data by using the following formulas.

$$
\begin{aligned}
& E R=\left|\frac{A E G-S E G}{A E G}\right| \times 100 \\
& M A P E=\sum_{i=1}^{n}\left|\frac{A E G_{i}-S E G_{i}}{A E G_{i}}\right| \times \frac{1}{n} \times 100
\end{aligned}
$$

where, AEG stands for actual electricity generation, SEG stands for simulation-based electricity generation, and $n$ stands for number of data.

The result of calculating ER and MAPE between actual electricity generation and simulation-based electricity generation showed that there are some data which the value of ER was too large to have sufficient reliability. Since it also resulted in a large MAPE value, the re-organization of the data was necessary. The study, thus, conducted an interview with the manager of the New Renewable Energy Monitoring System in KEMCO, and confirmed that there would be data error due to the malfunction of a monitoring system or a PV system. To exclude the outlier caused by these factors, the study used boxplot, a descriptive statistics method. Shown in the graph are the five-number summaries - the smallest observation, the lower quartile (Q1), the 
median (Q2), the upper quartile (Q3), and the largest observation, demonstrating that boxplot represents the characteristics of the data well [20]. Particularly, boxplot allows one to easily and conveniently discover outliers. As shown in Figure I, the boxplot (one of the functions in statistic package program, SPSS) was carried out to discover outliers of ER between actual and simulationbased electricity generation in February.

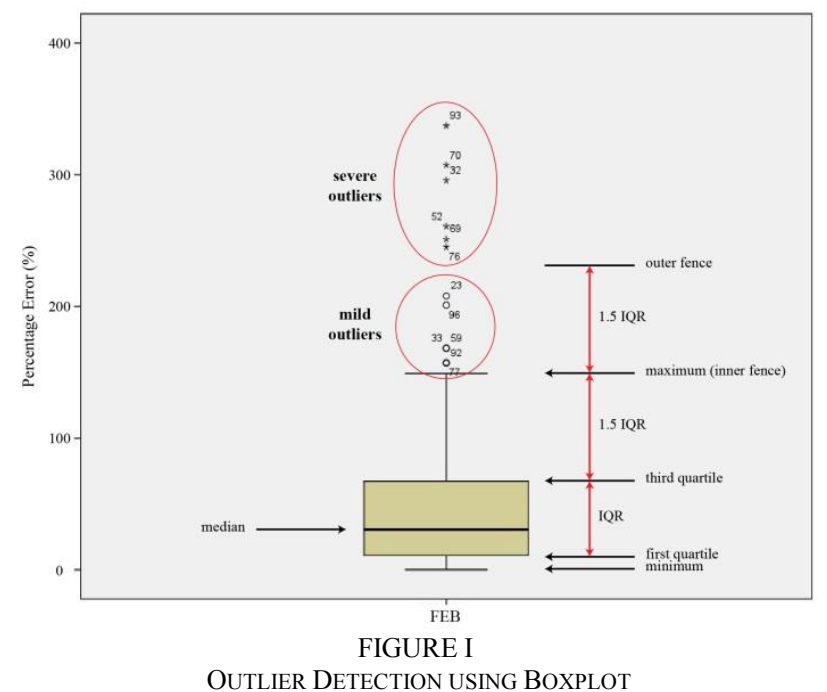

As shown in Figure I, the point that is 1.5 times of the interquartile range (IQR) apart from the upper quartile (Q3) is called the inner fence, and the data outside the point is defined as the mild outlier. Also, the point that is 3 times of the IQR apart from the Q3 is called the outer fence, and the data outside the point is defined as the severe outlier [21]. In this way, the study discovered outliers in the monthly ER from January to December, and excluded them from the data. Table II shows the number of monthly data before and after the exclusion of the outlier, as well as MAPE.

\section{B. Reason for uncertainty}

As such, errors always exist between actual and simulation-based electricity generation. There would be five reasons for such errors [22-25]: (i) climate factors (accumulation of snow, yellow dust, and high temperature); (ii) dirt, fallen leaves, bird feces, and other pollutants; (iii) careless maintenance; (iv) shading; and (v) error due to the data used in the energy simulation. If a PV panel is covered with snow, yellow dust, dirt, or other pollutants, it would be difficult to acquire sufficient surface area for the PV panel to induce electricity generation, resulting in loss in electricity generation. Thus, it is important to keep the PV panel clean through a systematic maintenance system. Also, the temperature and voltage of a solar cell are reciprocal to each other, and therefore, if the temperature of a PV panel rises in the summer, the voltage drops, resulting in lesser generation output. If a PV system is installed on the roof of a building, shading due to surrounding buildings or trees can also affect generation output. Finally, there could be errors due to the PV panel and inverter information used in the NRE simulation with 'RETScreen' in this particular study. It is because the PV panel and inverter information are data from the market research, not an actual data installed in public facilities in Seoul.

C. Comparative analysis between actual electricity generation and simulation-based electricity generation based on seasonality

Based on the above-mentioned reasons for errors, the study conducted an analysis on the MAPE between actual and simulation-based electricity generation that was calculated above. Toward this end, the study used the meteorological yearbook between 2008 and 2011, as published annually by KMA [19].

As shown in Table II, MAPE was high in winter, such as in January, February, November and December. The reasons for such a result are as follows. First, the huge accumulation of snow in the winter covers the surface of the PV panel, and the actual electricity generation of the PV system would be lower than the simulation-based electricity generation. According to the meteorological yearbook, there has been an accumulation of snow every year in January, February, November, and December in Seoul, South Korea, and in 2008, 2010, and 2011, it snowed even in March, though it was just a small amount. Especially, it snowed heavily in January and December in overall. Considering the highest MAPE in January and December, it is determined that the electricity generation of the PV system is largely affected by accumulated snow.

Second, the difficulty in maintaining the PV system in the winter resulted in poor system maintenance. Through the interview with the manager of PV systems in public facilities in Seoul, the study confirmed that the cold weather and heavy snow in the winter made it difficult to conduct regular maintenance work on the PV systems.

On the other hand, during the months other than those in the winter, MAPE was around 10 to $20 \%$. In the spring (March to May), MAPE in March and May was somewhat higher than that in April. According to the meteorological yearbook between 2008 and 2011, yellow dust occurred mainly in March and May in Seoul, South Korea, and the sand or dirt due to the yellow dust covering the PV panel could cause loss in electricity generation. Therefore, it is believed that there was power loss due to yellow dust in March and May.

In the summer (June to August), there would be errors due to high temperature and heavy rain. The MAPE in June to August is lower than that in the other months, and, therefore, it is believed that the error due to high temperature and heavy rain would be lower than that caused by snow accumulation or yellow dust. Also, the MAPE in July was somewhat higher than that in June or August. 
According to the meteorological yearbook, in 2008, 2009, and 2011, the precipitation in July was the largest, and, particularly, that in July 2011 was almost twice the precipitation in the other years. Therefore, it is determined that the higher MAPE in July than that in June or August is due to heavy rain.

TABLE II

COMPARATIVE EVALUATION OF ACTUAL ELECTRICITY GENERATION AND SIMULATION-BASED ELECTRICITY GENERATION

\begin{tabular}{ccccc}
\hline \multirow{2}{*}{ Month } & \multicolumn{2}{c}{ before excluding outliers } & \multicolumn{2}{c}{ after excluding outliers } \\
\cline { 2 - 5 } & num. of data & MAPE (\%) & num. of data & MAPE (\%) \\
\hline JAN. & 89 & 101 & 82 & $\mathbf{8 6}$ \\
FEB. & 100 & 55 & 84 & 21 \\
MAR. & 102 & 44 & 86 & 15 \\
APR. & 108 & 40 & 85 & 22 \\
MAY. & 111 & 60 & 94 & 10 \\
JUN. & 111 & 55 & 84 & 14 \\
JUL. & 112 & 53 & 88 & 8 \\
AUG. & 109 & 35 & 85 & 12 \\
SEP. & 108 & 36 & 86 & 28 \\
OCT. & 109 & 42 & 94 & $\mathbf{3 4}$ \\
NOV. & 113 & 64 & 100 & $\mathbf{4 1}$ \\
DEC. & 108 & 80 & 97 & $\mathbf{6 7}$ \\
\hline
\end{tabular}

D. Probability distribution of loss ratio between actual electricity generation and simulation-based electricity generation

To more accurately and realistically estimate the electricity generation of PV systems in advance, various errors that were analyzed above should be considered. Therefore, the study produced the Probability Distribution Function (PDF) of the monthly loss ratio between the actual and simulation-based electricity generation so as to consider various types of uncertainty in estimating the electricity generation of a PV system. Accordingly, to produce the PDF, the study used the function in 'Crystal Ball', called 'Fit'.

The PDF of the loss ratio between actual electricity generation and simulation-based electricity generation is applied to the simulation-based electricity generation in estimating the electricity generation of a PV system. Thus, the PDF should be produced by calculating the monthly loss ratio based on the simulation-based electricity generation. Below is the loss ratio equation based on the simulation-based electricity generation.

$L R=\frac{A E G-S E G}{S E G} \times 100$

where, LR stands for loss ratio, AEG stands for actual electricity generation, and SEG stands for simulation-based electricity generation. If LR is negative, it is shown that loss in electricity generation has occurred. If it is positive, it is shown that there was no loss in electricity generation; rather, there was gain in electricity generation.

The PDF produced as such is used as an assumption for Monte-Carlo Simulation (MCS) in the case study. A detailed explanation of this process shall be given in the case study.

Figure AI and Table AI of the appendix show the monthly PDF of the loss ratio between actual and simulation-based electricity generation result, as produced by using 'Crystal Ball'.

As shown in Figure AI, different PDF was produced every month, and in all the months from January to December, almost all loss ratios were in negative value. This means that in general, the value of the actual electricity generation was smaller than that of the simulation-based electricity generation. Thus, it is believed that the installation of a PV system would cause loss in electricity generation due to various kinds of uncertainty. Also, as the absolute value of the loss ratio, which is negative, becomes larger, the error due to the loss in electricity generation increases, which means there is large amount of loss in electricity generation. Particularly, according to Figure II, in the winter (January and December) when a large error due to climate factors (i.e., accumulated snow) is expected, loss ratio of both January and December was negative, while the absolute value was considerably larger than that of the other months. This means that compared to that in the other months, the loss in electricity generation in January and December was considerably larger. Furthermore, the left-sided PDF graph of January 
and December signifies that there were great amount of data with large loss in electricity generation in the winter (January and December). Consequently, it is determined that January and December generally have more cases of large loss in electricity generation.

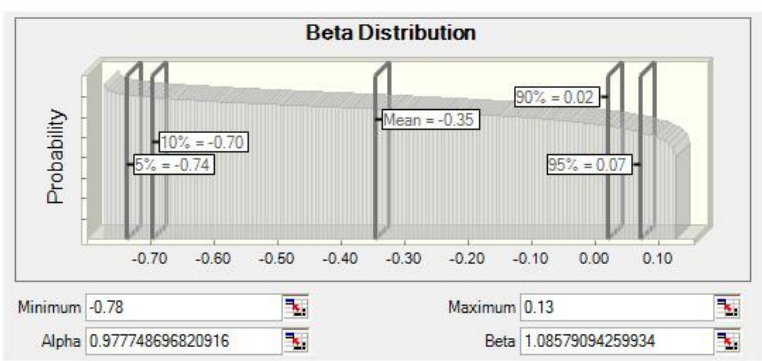

(A) JANUARY

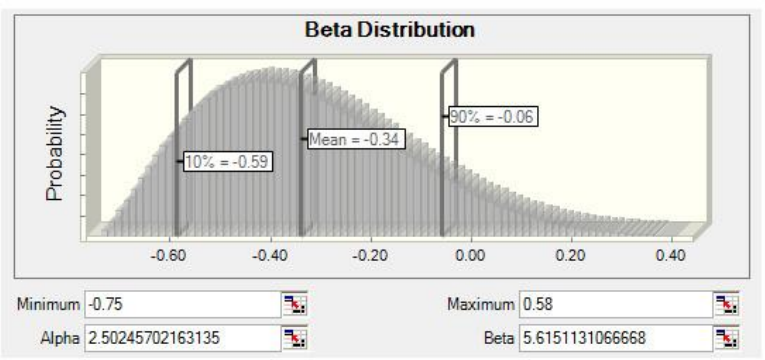

(B) DECEMBER

FIGURE II

PDF of Loss RATIO BETWEEN ACTUAL AND SiMULATION-BASED ELECTRICITY GENERATION

\section{CASE STUDY}

To estimate the electricity generation of a PV system while considering various kinds of uncertainty, the study performed MCS. The study applied the monthly PDF of the loss ratio between the actual and simulation-based electricity generation, as calculated above, to the MCS, and used 'Crystal Ball'.

To verify the validity of the aforementioned PDF, the case study was conducted using four public facilities with a PV system in Seoul, two in Gangbuk(north) and two in Gangnam(south), each of which has the actual electricity generation data in 2011 and 2010.

\subsection{Defining assumptions using MCS}

The study defined the monthly PDF of the loss ratio between the actual and simulation-based electricity generation as the assumption for MCS. The assumption defined as such was applied to the monthly simulationbased electricity generation of the selected four cases to produce the PDF of the monthly electricity generation. Finally, the study produced the PDF of the yearly electricity generation (i.e., MCS forecast factors) in which monthly electricity generations were summed up.

\subsection{Stochastic approach using MCS}

MCS was performed by defining all the monthly assumptions in the four cases, and after 1000 times of simulation, as shown in Figure III, the PDF of the annual electricity generation was produced. Using the resulting PDF, the study calculated the ER and MAPE of the simulation-based electricity generation compared to the actual electricity generation. Also, the simulation with stochastic approach (SA)-based electricity generation (simulation+SA-based electricity generation) was conducted to calculate the ER and MAPE compared to the actual electricity generation. Table AII of the appendix shows the comparison of these values.

As shown in Table III, in the Case 1, the actual electricity generation was $27.57 \mathrm{MWh}$, while the simulation-based electricity generation was $31.28 \mathrm{MWh}$, and the simulation+SA-based electricity generation was concluded as 26.44 MWh. The simulation-based electricity generation was based only on the use of 'RETScreen', while the simulation+SA-based electricity generation was based on the stochastic approach by combining both 'RETScreen' and MCS. Therefore, it was determined that the method combining the NRE simulation program and the stochastic approach (simulation with SA method) would result in a more accurate value than in the method that used only the NRE simulation program (simulation-only method) to estimate electricity generation. In the other cases (2-4), the simulation+SA-based electricity generation also produced smaller MAPE between the actual and simulation-based electricity generation (refer to Table AII of the appendix). Particularly, in Case 2 and Case 4, the error between the actual and simulation+SA-based electricity generation was $1 \%$ and $2 \%$, respectively, showing much improved estimation performance. If the electricity generation of a PV system is to be estimated based only on NRE simulation, it would fail to consider the loss in electricity generation that would occur in actual implementation, causing excessive loss in investment. Excessive loss of investment could be prevented by using the simulation with SA methodology, which would offer better estimation performance, and could help perform an effective decisionmaking process in implementing a PV system.

According to Figure III, in all cases (1-4), using simulationonly method resulted in the larger annual simulation-based electricity generation than the actual electricity generation. Using simulation with SA method resulted in the smaller simulation+SA-based electricity generation than the actual electricity generation in Cases 1, 2, and 4, with the exception of Case 3, where the result was the same as in the simulation-only method. In using the simulation with SA method, it is possible to consider the loss in electricity generation more excessively than it is in reality, and, therefore, it is important to collect more accurate and 
reliable information in the stage of data establishment. Furthermore, the implementation of the simulation with SA method would offer a range of the resulting value, rather than determining one value as the result, so that the final decision-maker could make informed decisions in various situations by considering uncertainties.

TABLE III

COMPARATIVE EVALUATION OF DETERMINISTIC APPROACH AND STOCHASTIC APPROACH FOR CASE 1

\begin{tabular}{|c|c|c|c|c|c|c|c|c|c|c|c|c|c|c|}
\hline \multicolumn{2}{|c|}{ Classification } & JAN. & FEB. & MAR. & APR. & MAY. & JUN. & JUL. & AUG. & SEP. & OCT. & NoV. & DEC. & Total \\
\hline Actual & EG & 1.933 & 2.043 & 3.521 & 3.027 & 3.045 & 2.598 & 1.695 & 2.136 & 2.633 & 2.656 & 1.445 & 1.034 & 27.57 \\
\hline \multirow{2}{*}{$\begin{array}{c}\text { Simulation } \\
\text {-only }\end{array}$} & EG & 0.150 & 2.001 & 3.041 & 3.113 & 2.901 & 2.666 & 1.00 & 2.142 & 2.84 & 2.695 & 1.535 & 2.096 & 31.28 \\
\hline & error & $63 \%$ & $24 \%$ & $10 \%$ & $3 \%$ & $2 \%$ & $3 \%$ & $11 \%$ & $0 \%$ & $8 \%$ & $1 \%$ & $6 \%$ & $103 \%$ & $13 \%$ \\
\hline \multirow{2}{*}{$\begin{array}{c}\text { Simulation } \\
\text { with } \mathrm{SA}\end{array}$} & EG & 2.048 & 2.032 & 3.157 & 2.783 & 2.648 & 2.55 & 1.77 & 2.077 & 2.622 & 2.231 & 1.134 & 1.389 & 26.44 \\
\hline & error & $6 \%$ & $1 \%$ & $5 \%$ & $8 \%$ & $13 \%$ & $2 \%$ & $4 \%$ & $3 \%$ & $0 \%$ & $16 \%$ & $22 \%$ & $34 \%$ & $4 \%$ \\
\hline
\end{tabular}

Note: EG=Electricity Generation (MWh)
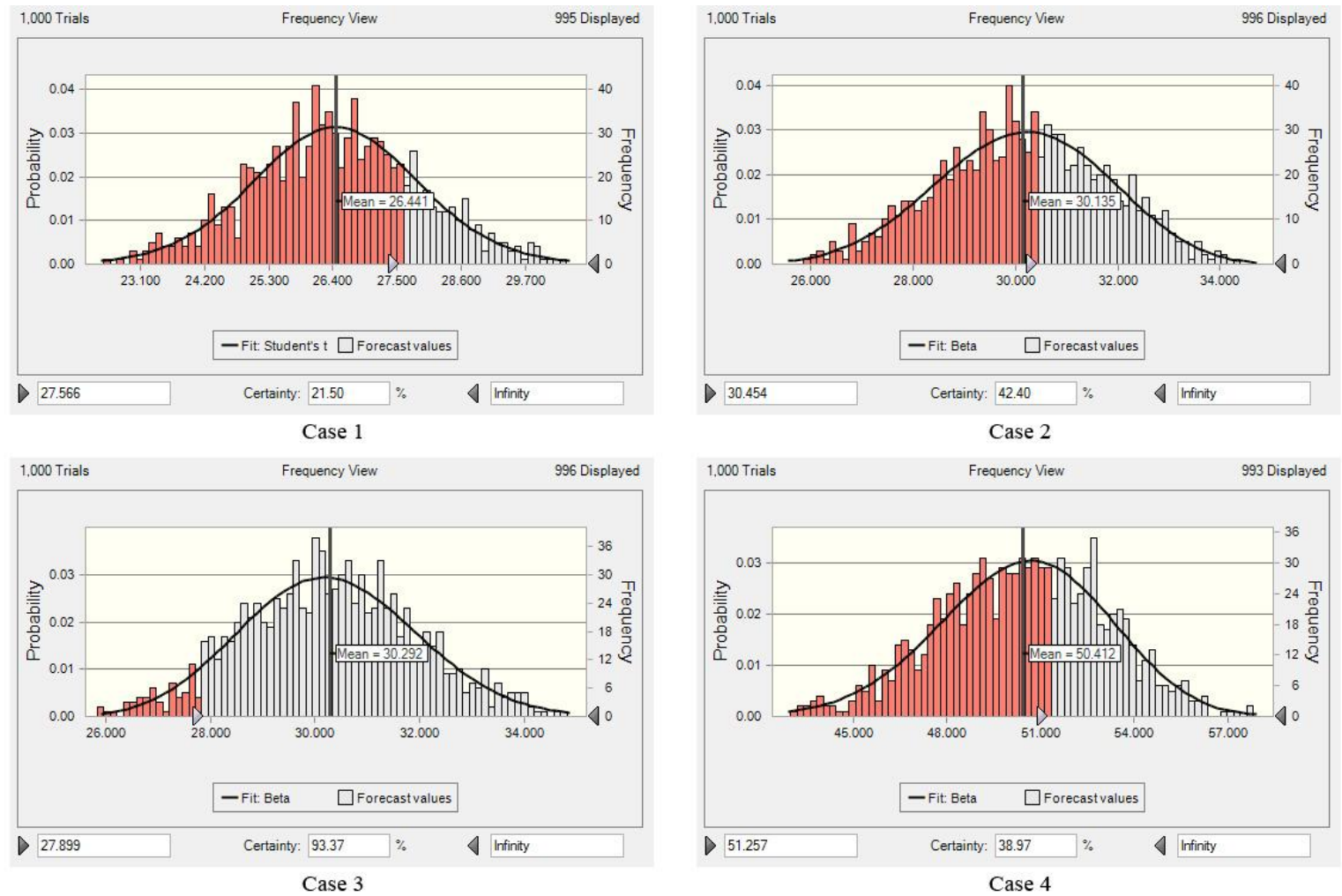

FIGURE III

PDF OF ANNUAL ELECTRICITY GENERATION

\section{CONCLUSIONS}

This study produced the loss ratio of the monthly electricity generation based on the analysis of the error between the actual and simulation-based electricity generation in implementing a PV system. Also, it aimed to estimate electricity generation more accurately and conveniently by applying the loss ratio by considering various kinds of uncertainty to the estimation of the electricity generation of a PV system. Toward this end, the study first collected the actual electricity generation data between 2008 and 2011 from PV system installed in public facilities and schools in Seoul. Based on the collected data, the study used the NRE simulation program, called 'RETScreen', to calculate the simulation-based electricity generation. Next, the study calculated the monthly MAPE between the actual and simulation-based electricity generation, and analyzed the causes for the error that considered seasonal variations. To apply such errors to the estimation of electricity generation of a PV system, the study produced the monthly PDF of the loss ratio between 
the actual and simulation-based electricity generation. Finally, the study conducted the MCS, of which the assumption was the monthly PDF, as produced above, and performed a case study on four cases. To produce the PDF and to conduct the MCS, the study used a program called 'Crystal Ball'. The results of this study can be summarized below.

First, the study calculated the MAPE between the actual and simulation-based electricity generation, and analyzed the errors. The result showed that in the winter-namely, January, February, November, and December-MAPE was relatively higher, up to $86 \%$ at maximum, than that in the other months, when it was only between 10 and 20\%. Due to heavy accumulation of snow and the difficulty in maintenance, there were large MAPE values in the winter. There could be errors in the spring due to yellow dust, and in the summer due to high temperature and heavy rain.

Second, the study could consider various types of uncertainty in estimating the electricity generation of a PV system by producing the monthly PDF of the loss ratio between the actual and simulation-based electricity generation. PDF had various probability distributions by month, and both January and December (winter) had beta distribution, in which the minimum value was -0.78 and 0.75 , respectively. The loss in electricity generation in these two months was considerably larger than that of the other months.

Third, to estimate the electricity generation of a PV system, the study conducted the MCS by using the monthly PDF of the loss ratio between the actual and simulationbased electricity generation, which was produced above. Furthermore, the study conducted a case study to verify the validity of the PDF. The result showed that in all four cases, the simulation+SA-based electricity generation, based on the simulation with SA method, produced a smaller error value against the actual electricity generation than the simulation-based electricity generation, based on the simulation-only method. Therefore, it was determined that the simulation with SA method offered better estimation performance. It was also determined that the stochastic approach (simulation with SA method) would offer various choices, providing various possibilities in the decisionmaking process.

The results of this study could be used (i) to estimate electricity generation from a PV system more accurately before installation of the system, (ii) to establish the optimal maintenance strategy for different application fields and different seasons, and (iii) to conduct a feasibility study on investment prospects at the level of the life cycle.

In relation to this study, future research will focus on the following issues: i) multilateral analysis on the power loss factors in a PV system; ii) stochastic approach of a PV system electricity generation estimation that considers various kinds of uncertainty (i.e., power loss, solar radiation estimation, etc.); and iii) reviews and proposals to reduce power loss in a PV system.

\section{ACKNOWLEDGEMENT}

This research is supported by a grant from High-Tech Urban Development Program (11CHUD-G03) funded by the Ministry of Land, Transport and Maritime affairs, South Korea. This research is also supported by the National Research Foundation of Korea (NRF) grant funded by the Korean government (Ministry of Education, Science and Technology, MEST) (No. 2012-004376).

Note: This paper was originally published as the conference paper in the ICCEPM 2013 and awarded as one of the best papers. Through a rigorous review process, the paper has been invited to be a special version of JCEPM.

\section{REFERENCES}

[1] T.H. Hong, H.J. Kim, T.H. Kwak, "Energy Saving Techniques for Reducing $\mathrm{CO}_{2}$ Emission in Elementary Schools", Journal of Management in Engineering, vol. 28, no. 1, pp. 1-12, 2012.

[2] T.H. Hong, J.M. Kim, C.W. Koo, "LCC and $\mathrm{LCCO}_{2}$ analysis of green roofs in elementary schools with energy saving measures", Energy and Buildings, vol. 45, no. 2, pp. 229-239, 2012.

[3] International Energy Agency, "World Energy Outlook 2010", International Energy Agency, 2010.

[4] Ministry of Knowledge Economy (MKE), "Report on formation of expanded foundation through solar potential survey", Ministry of Knowledge Economy (MKE), 2011

[5] New Renewable Energy Center in the Korea Energy Management Corporation(KEMCO), http://www.energy.or.kr/

[6] Korea Mechanical Construction Contractors Association(KMCCA), "Seoul New Renewable Energy Travel", Monthly Journal of KMCCA, January, pp. 36-53, 2011.

[7] T. Oozekia, T. Izawaa, K. Otanib, K. Kurokawaa, "An evaluation method of PV systems", Solar Energy Materials \& Solar Cells, vol. 75, no. 3-4, pp. 687-695, 2003.

[8] D. Thevenard, S. Pelland, "Estimating the uncertainty in long-term photovoltaic yield predictions", Solar Energy, 2011. Article in press.

[9] N. Martin, J.M. Ruiz, "Calculation of the PV modules angular losses under field conditions by means of an analytical model", Solar Energy Materials \& Solar Cells, vol. 70, no. 1, pp. 25-38, 2001.

[10] C. Carrero, J. Rodri'guez, D. Ramı'rez, C. Platero, "Simple estimation of PV modules loss resistances for low error modeling", Renewable Energy, vol. 35, no. 5, pp. 1103-1108, 2010.

[11] W.R. Anis, M.A.-S. Nour, "Energy losses in photovoltaic systems", Energy Conversion and Management, vol. 36, no. 2, pp. 1107-1113, 1995.

[12] J. Zorrilla-Casanova, M. Piliougine, J. Carretero, P. BernaolaGalván, P. Carpena, L. Mora-López, M. Sidrach-de-Cardona, "Losses produced by soiling in the incoming radiation to photovoltaic modules", Progress in photovoltaics: research and applications, 2012. doi:10.1002/pip.1258.

[13] O. Perpin an, E. Lorenzo, M.A. Castro, "On the Calculation of Energy Produced by a PV Grid-Connected System", Progress in photovoltaics: research and applications, vol. 15, no. 3, pp. 265-274, 2007.

[14] Y. Ueda, K. Kurokawa, K. Kitamura, M. Yokota, K. Akanuma, H. Sugihara, "Performance analysis of various system configurations on grid-connected residential PV systems", Solar Energy Materials \& Solar Cells, vol. 93, no. 6-7, pp. 945-949, 2009.

[15] New Renewable Energy Monitoring System in the Korea Energy Management Corporation(KEMCO), http://konesis.kemco.or.kr/.

[16] California Energy Commision Energy Technology Development Division, "A guide to photovoltaic(PV) system design and installation", $1^{\text {st }}$ ed., CA: Endecon Engineering, 2001.

[17] S. Ubertini, U., Desideri, "Performance estimation and experimental measurements of a photovoltaic roof", Renewable Energy, vol. 28, pp. 1833-1850, 2003. 
[18] J.W. Ju, H.S. Kim, S.J. Oh, M.S. Lee, J.M. Choi, "A study on the difference of regional electricity and economic comparative valuation of the photovoltaic system", Conference of Korea Institute of Architectural Sustainable Environment and Building Systems, pp. 137-140, 2008.

[19] Korea Meteorological Administration, "Annual Climatological Report", Korea Meteorological Administration, 2008-2011.

[20] H.S. Lee, J.H. Lim, "Statistical package for the social science(SPSS) 18.0 manual", Seoul: JypHyunJae Publishing Co., 2011.

[21] M. Frigge, D.C. Hoaglin, B. Iglewicz, "Some Implementations of the Boxplot”, The American Statistician, vol. 43, no. 1, pp. 50-54, 1989.

[22] G.M. Tina, , S. De Fiore, C. Ventura, "Analysis of forecast errors for irradiance on the horizontal plane", Energy Conversion and Management, 2012. Article in press.

[23] A. Chouder, A. Silvestre, "Automatic supervision and fault detection of PV systems based on power losses analysis", Energy Conversion and Management, vol. 51, no. 10, pp. 1929-1937, 2010.

[24] H.-K. Choi, S.-G. Choi, D.-W. Choi, G.-M. Lee, "Summer, A Study on Characteristic by Photovoltaic Module by Climate Fluctuation", Journal of the Korean Institute of Illuminating and Electrical Installation Engineers, vol. 23, no. 12, pp. 75-82, 2009.

[25] J.-H. So, B.-G. Yu, H.-M. Hwang, G.-J. Yu, J.-Y. Choi, "Performance Monitoring Results, Evaluation and Analysis of 50kW Grid-Connected PV System", Journal of the Korean Solar Energy Society, vol. 27, no. 2, pp. 29-35, 2007. 


\section{APPENDIX A: SUPPLEMENTARY MATERIAL}

TABLE AI

MONTHLy PDF of LOSS RATIO BETWEen ACTUAL ELECTRICITY GENERATION AND SimUlATION-BASED ELECTRICITY GENERATION

\begin{tabular}{|c|c|c|c|c|c|}
\hline \multirow{2}{*}{ JAN. } & distribution & $\min$ & $\max$ & alpha & beta \\
\hline & beta & -0.78 & 0.13 & 0.97774869682092 & 1.08579094259934 \\
\hline \multirow{2}{*}{ FEB. } & distribution & mean & scale & & \\
\hline & logistic & -0.2 & 0.1 & & \\
\hline \multirow{2}{*}{ MAR. } & distribution & $\min$ & $\max$ & alpha & beta \\
\hline & beta & -0.54 & 0.11 & 2.50321151880299 & 1.54075085687052 \\
\hline \multirow{2}{*}{ APR. } & distribution & location & scale & shape & \\
\hline & weibull & -0.7 & 0.65 & 6.05514105333116 & \\
\hline \multirow{2}{*}{ MAY. } & distribution & likeliest & scale & & \\
\hline & minimum extreme & -0.04 & 0.12 & & \\
\hline \multirow{2}{*}{ JUN. } & distribution & mean & std. Dev. & & \\
\hline & normal & -0.05 & 0.1 & & \\
\hline \multirow{2}{*}{ JUL. } & distribution & location & scale & shape & \\
\hline & weibull & -0.92 & 0.92 & 7.25505390378477 & \\
\hline \multirow{2}{*}{ AUG. } & distribution & location & mean & std. Dev. & \\
\hline & lognormal & -1.37 & -0.03 & 0.09 & \\
\hline \multirow{2}{*}{ SEP. } & distribution & mean & scale & & \\
\hline & logistic & -0.08 & 0.06 & & \\
\hline \multirow{2}{*}{ OCT. } & distribution & mean & std. Dev. & & \\
\hline & normal & -0.18 & 0.15 & & \\
\hline \multirow{2}{*}{ NOV. } & distribution & mean & scale & & \\
\hline & logistic & -0.25 & 0.11 & & \\
\hline \multirow{2}{*}{ DEC. } & distribution & $\min$ & $\max$ & alpha & beta \\
\hline & beta & -0.75 & 0.58 & 2.50245702163135 & 5.61511310666680 \\
\hline
\end{tabular}




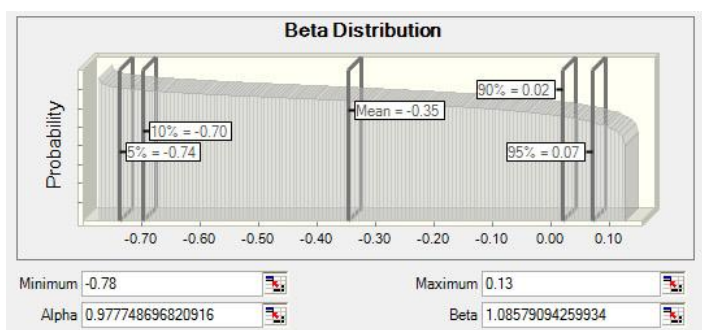

JAN.
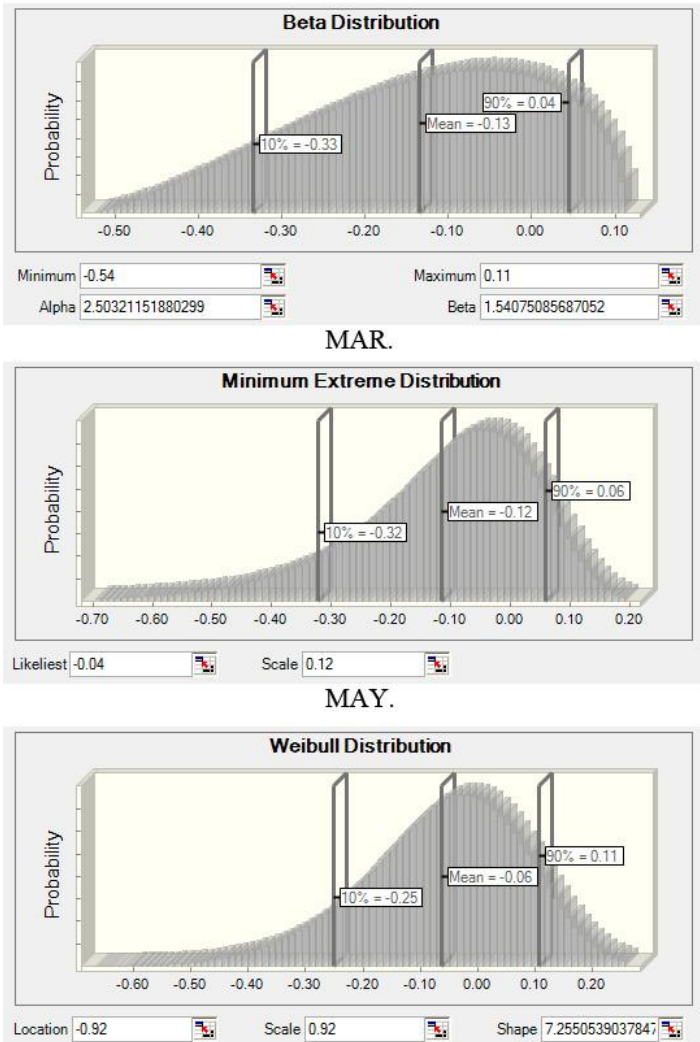

JUL.

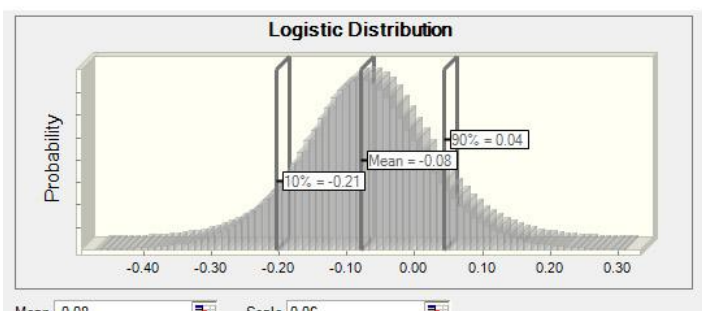

\begin{tabular}{rrr}
\hline Mean $-0.08 \quad$ Scale 0.06 \\
& SEP.
\end{tabular}

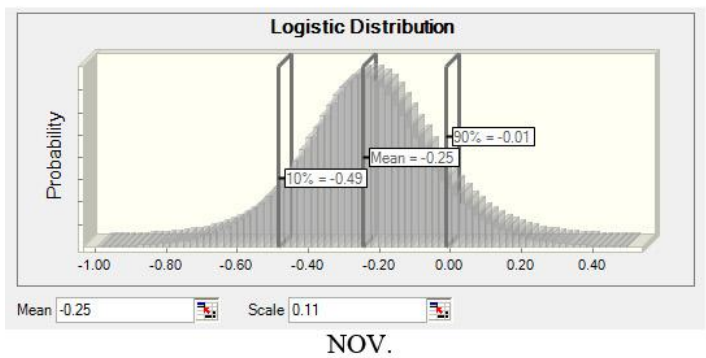

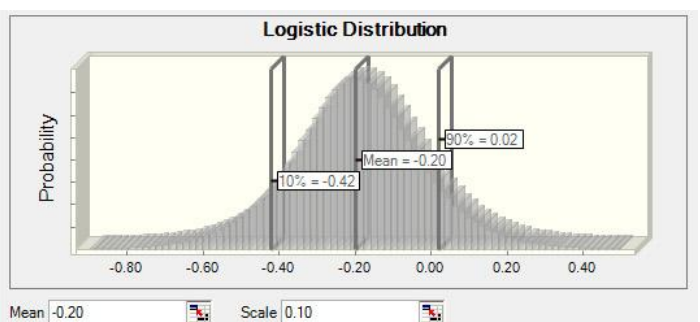

FEB.
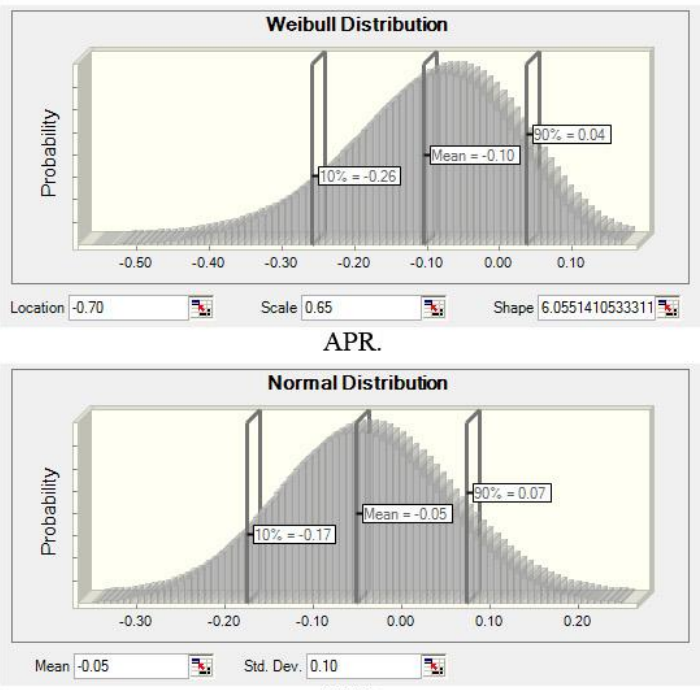

JUN.

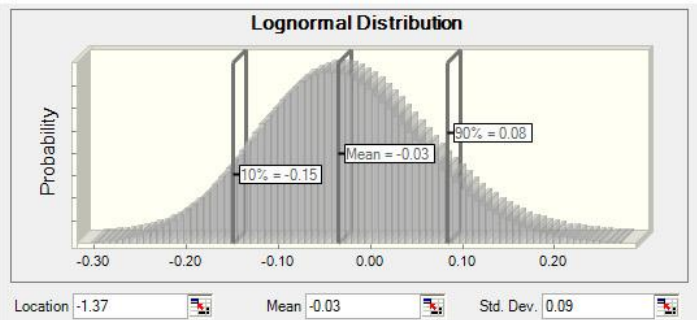

AUG.

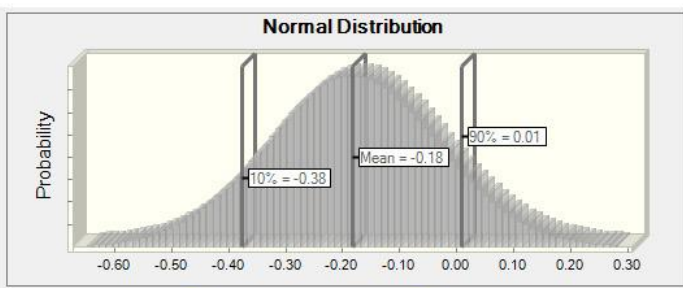

Mean -0.18 St. Dev. 0.15

OCT.

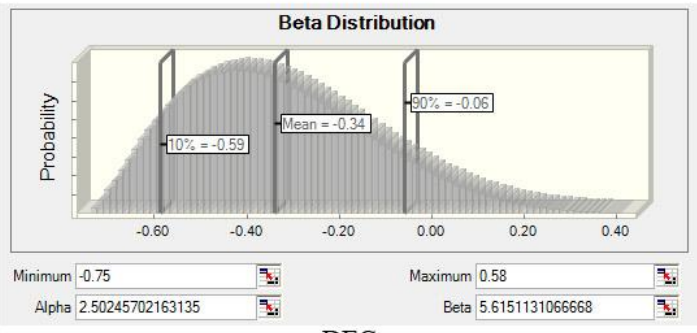

DEC.

FIGURE AI

MONTHLY PDF OF LOSS RATIO BETWEEN ACTUAL ELECTRICITY GENERATION AND SiMULATION-BASEd ELECTRICITY GENERATION 


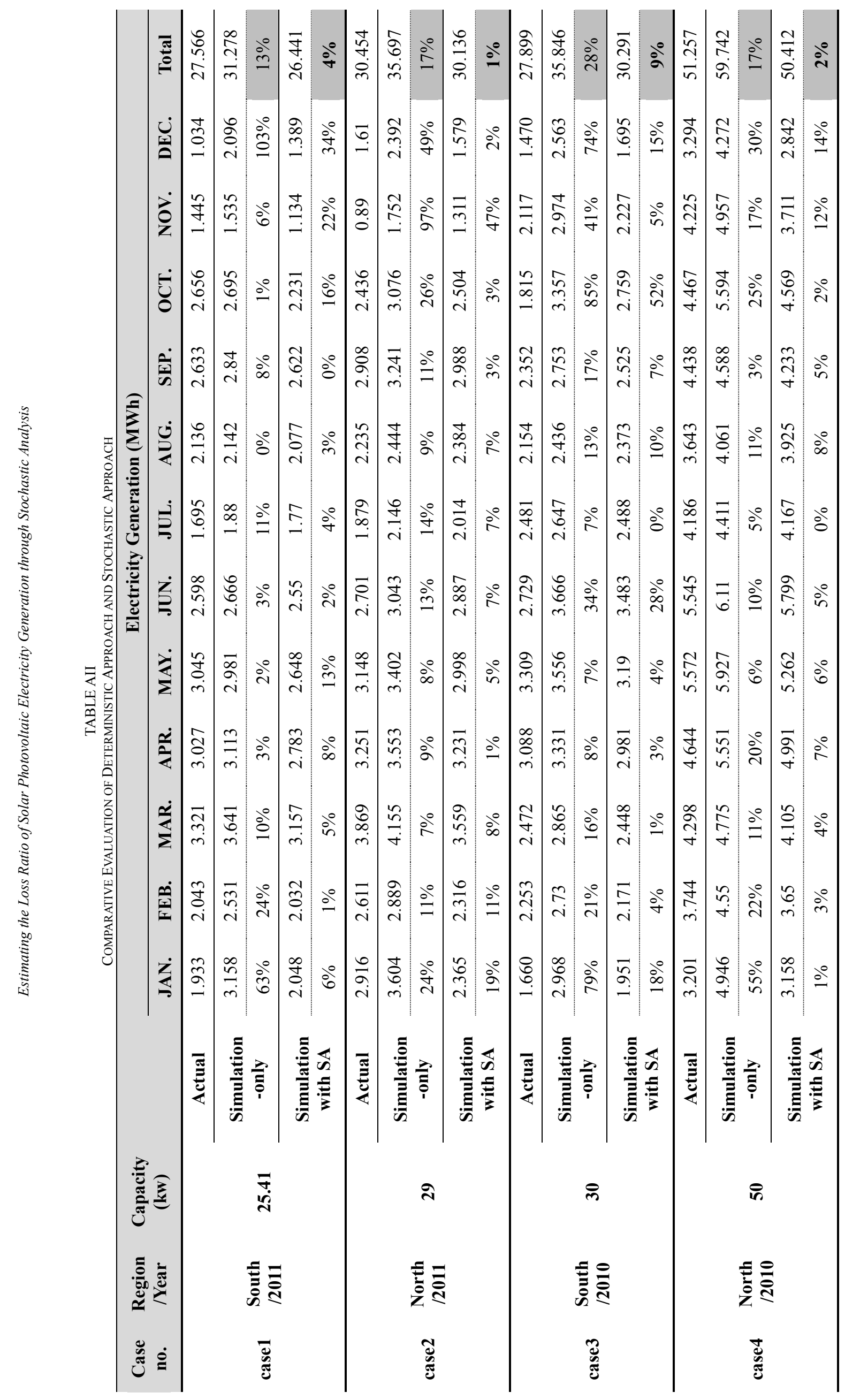

